\title{
Novel endoscopic approach to resection of large symptomatic duplication cysts
}

We present the case of a 51-year-old man with dysphagia to solids and occasional retrosternal chest pain. Computed tomography of the chest revealed an esophageal mass, which on endoscopy was just distal to the gastroesophageal junction. An esophagram found a delay in the passage of contrast as a result. An endoscopic ultrasound (EUS) demonstrated an anechoic/hypoechoic third layer cyst, with internal debris and a redundancy of layers, consistent with a large duplication cyst. Although definitive management is surgical excision, simple endoscopic fenestration has been described [1,2]; however, there remains a concern about recurrence in the long term. We offered the patient a novel endoscopic approach aimed at complete excision of the luminal cyst wall, reducing any long-term recurrence ( $\triangleright$ Video 1 ).

The cyst was punctured using a 19-gauge EUS needle. Saline with methylene blue was injected into the cyst to increase its size and stain the internal cyst wall blue, making an endoscopic excision safer. An electrosurgical knife was used to create an initial incision along the lateral margin, and endoscopic submucosal dissection (ESD) was performed until we identified the cyst roof, which was stained blue. The knife was used to perforate the cyst, resulting in an immediate flow of methylene blue-stained cyst fluid. The entire roof was then resected en bloc in a circumferential manner using an insulatedtip knife. With the internal cavity comple-

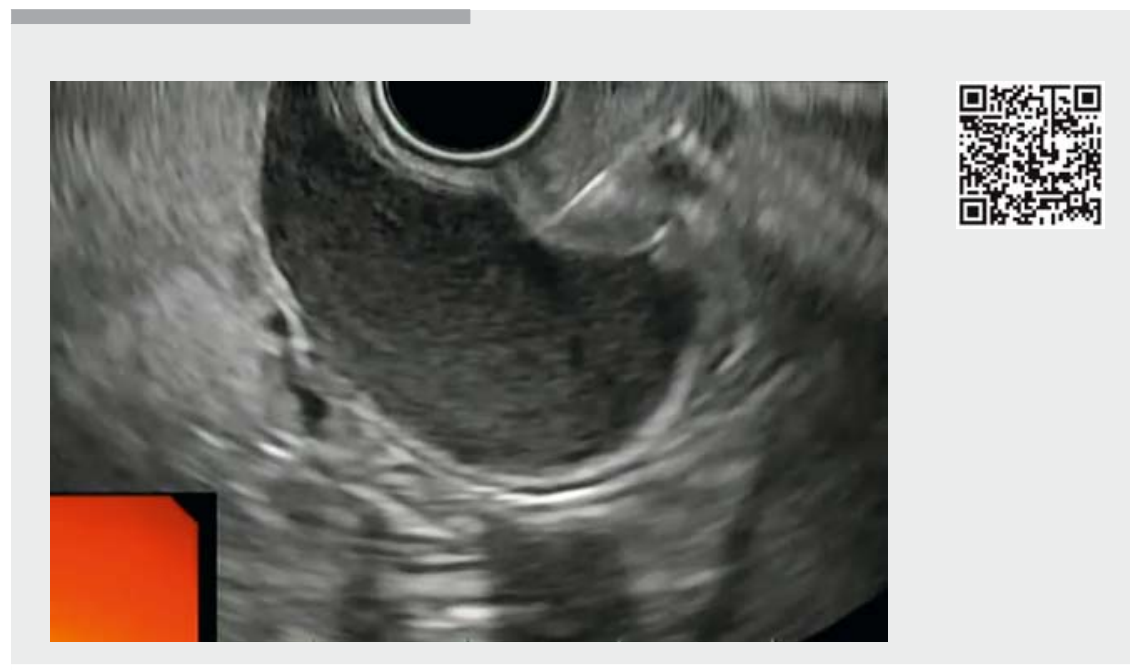

Video 1 Endoscopic management of a large duplication cyst.

tely exposed, the lining was irrigated and inspected. The edges of the cyst were clipped circumferentially to prevent both delayed bleeding and premature closure. This is the first description of an ESD technique for treatment of a duplication cyst. Pre-injecting the cyst seems to make dissection easier and safer. The result is a complete unroofing and marsupialization of the cyst cavity. This may be a potentially superior approach for the treatment of duplication cysts and may help to reduce the risk of recurrence.

Endoscopy_UCTN_Code_TTT_1AO_2AN
Competing interests

Dr. Carr-Locke is a consultant for Olympus America.

The authors

Lionel S. D'Souza ${ }^{1}$, Arvind J. Trindade ${ }^{2}$, Brian Markowitz ${ }^{2}$, David L. Carr-Locke ${ }^{3}$, Petros C. Benias $^{2}$

1 Stony Brook University Hospital, New York, United States

2 North Shore University Hospital, New York, United States

3 New York Presbyterian/Weill Cornell Medical Center, New York, United States 


\section{Lionel S. D'Souza, MD}

Division of Gastroenterology and

Hepatology, Stony Brook University Hospital, 101 Nicolls Road, Health Sciences Tower Level 17, Room 060, Stony Brook, New York 11794-8410, United States

Fax: +1-631-444-8886

dsouza.lionel@gmail.com
[1] Ivekovic H, Jouret-Mourin A, Deprez PH. Endoscopic fenestration of esophageal duplication cysts. Endoscopy 2012; 44 (Suppl. 02): E404-E405

[2] Nishikawa J, Nagao M, Ogawa R et al. Endoscopic treatment of an esophageal duplication cyst. Endoscopy 2017; 49 (Suppl. 01): E107-E108

\section{Bibliography}

DOI https://doi.org/10.1055/a-0605-2630

Published online: 12.6 .2018

Endoscopy 2018; 50: E208-E209

(c) Georg Thieme Verlag KG

Stuttgart · New York

ISSN 0013-726X
ENDOSCOPY E-VIDEOS

https:/|eref.thieme.de/e-videos

口回 Endoscopy E-Videos is a free 然 access online section, reporting 回: on interesting cases and new techniques in gastroenterological endoscopy. All papers include a high quality video and all contributions are freely accessible online.

This section has its own submission website at

https://mc.manuscriptcentral.com/e-videos 